\title{
Comparison of Different Models for Higher Harmonics Resonance Analysis Between Traction Networks and High Speed Train
}

\author{
Hu Cao ${ }^{1, \text { a }}$, Yuping Liu ${ }^{1, b}$,Runze Zhang ${ }^{2, \mathrm{c}}$,Shuihui Liu ${ }^{2, \mathrm{~d}}$,Fei Lin ${ }^{2, \mathrm{e}}$ \\ ${ }^{1}$ CCRC QINGDAO SIFANG ROLLING STOCK RESEAARCH INSTITUTE CO.,LTD, \\ QINGDAO, 26600, China \\ 2 BEIJING JIAOTONG UNIVERSITY,BEIJING,100000,China \\ aemail:cao_hu123@126.com, bemail:13792844397@163.com; cemail:12291057@bjtu.edu.cn
}

Keywords: Tranction Networks; Mathematic model; Lumped parameter model; Distributed parameter model.

\begin{abstract}
With the rapid development of high-speed railway technology, more and more countries enjoy the convenience which travels with high speed train.Most of the high speed train running on the railway use distributed power technology, the converter on the train get power from traction network to supply the traction motors. In the actual line,4-quadrant converter's(4QC) switching actions will inject harmonic into the traction network, while it may lead to the problem of the coupling resonance of the network when the harmonics match with the network's impedance.Therefore,in analysis of practical problems,it plays an important role if the model of the netwoek is accurate. This paper will analyze and have a comparation with the difference and accuracy of three different traction network modeling methods.
\end{abstract}

\section{Introduction}

In the electrified railway system, sinusoidal pulse width modulation (SPWM) has been applied for more than twenty years. SPWM in the traction power supply system will produce higher harmonic.these harmonics can be filtered out by the leakage inductance of traction transformer under normal circumstance[1,2]. But because the traction power supply system is a distributed system, when the leakage inductance of the transformer is matched with the impedance value of the traction network, while the frequence of the harmonic current is the resonant frequency of the impedance value, it is likely to cause the coupling resonance of the vehicle network, and cause the distortion of the network voltage. Accidents due to the resonance of the vehicle network also occur in recently years,for example, the resonance happened in the experimental investigation of China's Beijing-Shanghai high-speed railway, resulting in theserious distortion of pantograph voltage, and finally leading to the breakdown of the vehicle-mounted arrestor. Similar resonances also happened in many other high-speed railway systems in China,and severely disrupted the normal railway operations[3].

There are a lot of resonance modeling methods for traction network.In paper [4],it established a simplified model for traction network using T-type distributed model. The main traction network model, two-port or four-terminal network[5],[6],[7], is effective in the analysis on single-line railway, but weak when applied to double-track or more wires involved traction network. The model which is often used in the power system is the distributed parameter model, the distributed parameter model uses traveling wave theory, and the simulation is more accurate, but due to the simulation step size is limited, a unit length of distributed parameter model is chosen for a longer length,it's not conducive to the precision analysis of traction network.

In this paper,the differences among the $\pi$ model, multi conductor chain network model and dietributed parameters line model will be analysed based on the simulation which uses direct power supply network with the return conductor wire. 


\section{Traction Network Model and Power System Harmonic Source}

In this chapter, the main source and composition analysis of harmonic in traction power supply system are introduced firstly.And then,it will introduce the theory of $\pi$ model, multi conductor chain network model and the distributed parameter model.

\subsection{Traction Power Supply System Harmonic Source}

It can be regarded as a vehicle network coupling system composed of traction network and train. It can ignore the background harmonics of the traction network if the traction network is an ideal power supply network.

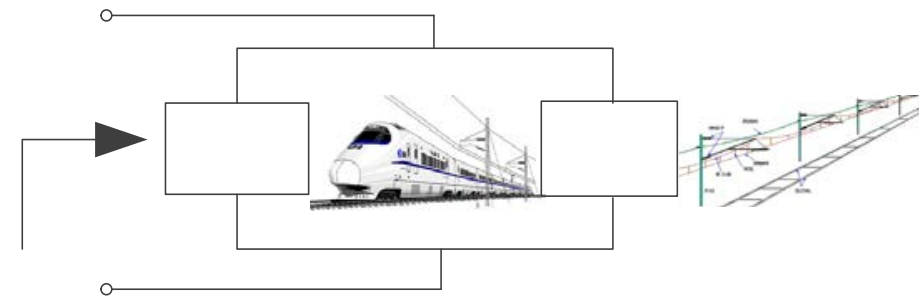

Fig.1. Traction Power Supply System

When the high speed train runs on the line, the train gets power through the pantograph,and then, it is connected to a four quadrant converter by the traction transformer on the train.In traction condition,it will rectifie AC for DC. The schematic diagram of a three level four quadrant converter is shown in Figure 2.

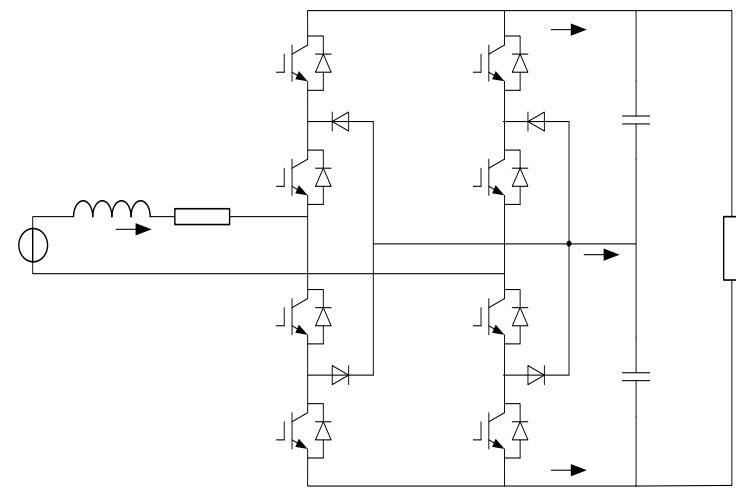

Fig.2. Three Level Four Quadrant Converter

Through the modulation theory of the three level four quadrant converter and double Fourier transform, the Fourier expression of the input terminal current can be obtained:

$$
i_{N}(t)=\frac{\sqrt{M^{2} U_{d}^{2}-2 U_{N}^{2}}}{\omega_{m} L_{N}} \cos \left(\omega_{m} t+\beta\right)+\sum_{m=2,4 \ldots n= \pm 1, \pm 3 . . .}^{\infty} \frac{2 U_{d}}{m \pi L_{N}\left(m \omega_{c}+n \omega_{m}\right)} J_{n}(m \pi M) \sin \frac{n \pi}{2} \sin \left(m \alpha+n \beta+m \omega_{c} t+n \omega_{m} t\right) \quad(1)
$$

In this formula, $\omega_{\mathrm{c}}$ is switch frequency, $\omega_{\mathrm{m}}$ is voltage of network frequency, $M$ is modulation, $U_{d}$ is DC voltage amplitude, $U_{d}$ is the rms of the network voltage, $L_{N}$ is the AC side inductor.It is obvious that the harmonic component in the input current is concentrated on the high order harmonic wave in the vicinity of even number of times .the switch frequence.The harmonic content is affected by the modulation, DC voltage amplitude, network voltage, switch frequency and network frequency. The input current can be seen as the fundamental component which frequency is equal to the voltage of the traction network and the other harmonic component. The fundamental component is the current obtained from the traction network, harmonic is generated by the four quadrant converter switch device action,and it will inject into the network through pantograph. So the train is harmonic source for the traction power supply system,

\subsection{Traction Network Modeling Method}

\subsection{1 $\pi$ Model}

The traction network equivalent circuit is shown in Figure 3, Zsn is the equivalent impedance of 
the system side, $Z 1 n, Z 2 n, Y 1 n, Y 2 n$ is the equivalent parameters of traction network on both sides of the train., $i_{a b n}$ is the train of the equivalent Norton current source, $L n$ is the equivalent inductance of train network side.

Impedance and admittance parameters shown in the figure of the circuit parameters are calculated by Carson theory, in the practical application, the wires are necessary to be combined.This model can be adopted to simplified the traction network when focus are the voltange and current in the position of train.

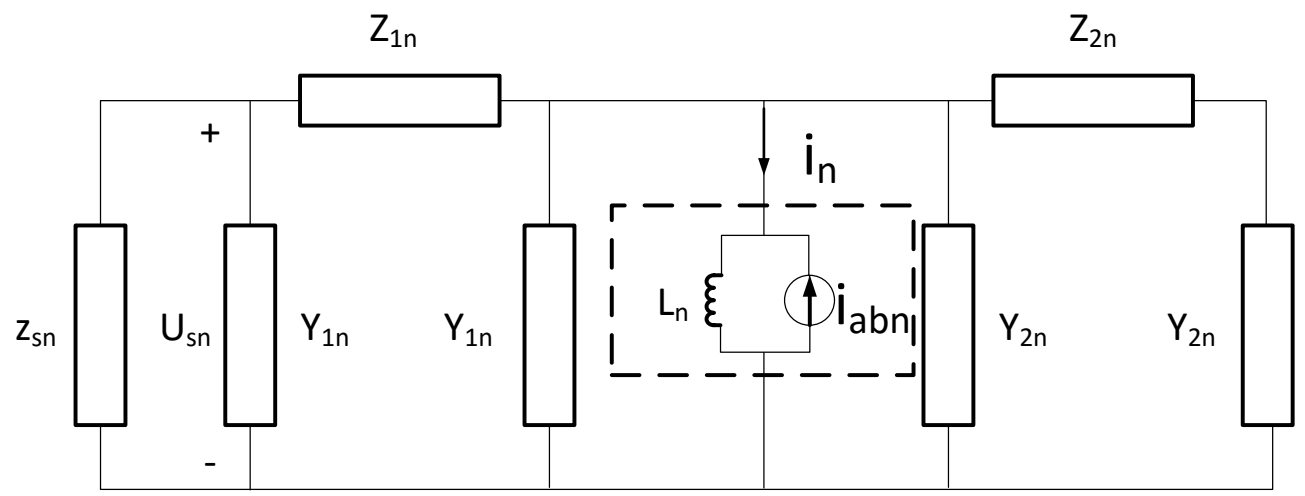

Fig.3. The Equivalent of Traction Network

\subsubsection{Multi Conductor Chain Network Model}

The high speed railway is a parallel multi conductor transmission line model composed of the power supply network and the return line. According to the network structure characteristics of traction power supply system and the actual position of the train, the equivalent model is a chain network model as shown in Figure 4, and it consists of series and parallel elements. $Z$ and $Y$ represent the impedance and admittance matrix,I is the current which injected into traction network by substation and train.

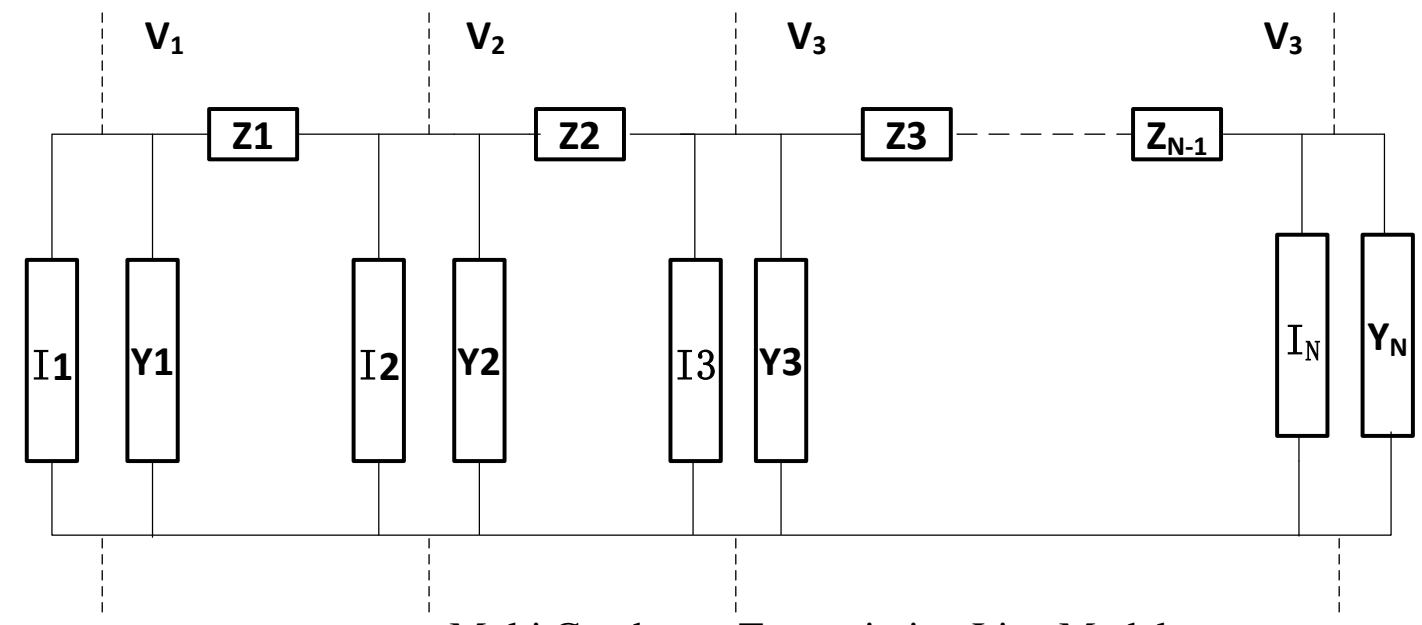

Fig.4. Multi Conductor Transmission Line Model

The impedance and admittance matrix of unit length is $Z$ and $Y$, it can calculate the line parameter formula for a length of $l$ as follows by using the principle of distributed parameter line:

$$
\left\{\begin{array}{l}
Z_{l}=Z l \frac{\sinh \gamma l}{\gamma l} \\
\frac{Y_{l}}{2}=\frac{Y}{2} l \frac{\tanh \gamma l / 2}{\gamma l / 2}
\end{array}\right.
$$

$\omega_{c}$ is the transmission coefficient of the line.Multi conductor chain model is the most widely used model in the traction power supply network model,it can restore the location of each component of the traction power supply system. When the length of a traction power supply line is determined, the more unit model is used, the more accurate the analysis of the characteristic of high frequency impedance is. 


\subsubsection{Distributed Parameters Line Model}

Distributed parameter model is based on the traveling wave theory, it needs to know the forward and backward traveling wave to calculate the electrical quantity. This model can be used to calculate the impedance value of any length line in theory. But in the digital simulation system, it is necessary to know the backward traveling wave to calculate the line parameters,so the length of the single line in simulation is larger than the product of the wave velocity and the simulation sampling step. So in the simulation, the selection of distribution parameters is often limited by the sampling step.

In a variety of programs using distributed parameters (e.g., EMTP), Bederon model algorithm is often used to convert the distributed parameter elements into Lumped parameter elements,it uses lumped parameter to calculate the wave process.

For a lossless line, the electrical parameters of the moment are calculated as follows:

$\left\{\begin{array}{l}e_{r}(\mathrm{t})-Z_{c} i_{r}(t)=e_{s}(t-\tau)+Z_{C} i_{s}(t-\tau) \\ e_{s}(\mathrm{t})-Z_{c} i_{s}(t)=e_{r}(t-\tau)+Z_{C} i_{r}(t-\tau)\end{array}\right.$

Which $e_{r}, e_{s}, i_{r}, i_{s}$ represent a two port network on both sides of the electrical quantity.

\section{Comparison of Different Modeling Methods with Simulation}

It uses three different models to build a $20 \mathrm{~km}$ long line with equivalent five conductor model. Simulation parameters are as follows:

Table1. Impedance $[\Omega / \mathrm{km}]$

\begin{tabular}{|c|c|c|c|c|c|}
\hline & Contact wire1 & Feeder 1 & Contact wire2 & Feeder 2 & Rail \\
\hline Contact wire1 & $2.63+0.0121 \mathrm{i}$ & $2.156+0.0036 \mathrm{i}$ & $2.19+0.0039 i$ & $2.14+0.0029 i$ & $2.32+0.0034 i$ \\
\hline Feeder 1 & $2.156+0.0036 \mathrm{i}$ & $2.336+0.0115 i$ & $2.146+0.0029 i$ & $2.094+0.0024 \mathrm{i}$ & $2.276+0.0030 \mathrm{i}$ \\
\hline Contact wire2 & $2.19+0.0039 \mathrm{i}$ & $2.146+0.0029 i$ & $2.630+0.0121 \mathrm{i}$ & $2.158+0.0037 i$ & $2.313+0.0030 \mathrm{i}$ \\
\hline Feeder 2 & $2.14+0.0029 i$ & $2.094+0.0024 \mathrm{i}$ & $2.158+0.0037 i$ & $2.334+0.0115 i$ & $2.261+0.0025 \mathrm{i}$ \\
\hline Rail & $2.32+0.0034 i$ & $2.276+0.0030 \mathrm{i}$ & $2.313+0.0030 \mathrm{i}$ & $2.261+0.0025 i$ & $3.785+0.0084 \mathrm{i}$ \\
\hline \multicolumn{6}{|c|}{ Table1. Capacitance [F/km] } \\
\hline & Contact wire1 & Feeder 1 & Contact wire2 & Feeder 2 & Rail \\
\hline Contact wire1 & $6.9462 \mathrm{e}-9$ & $1.9855 \mathrm{e}-9$ & $3.2711 \mathrm{e}-9$ & $7.1693 \mathrm{e}-10$ & $2.3967 e-9$ \\
\hline Feeder 1 & $1.9855 \mathrm{e}-9$ & $6.1529 \mathrm{e}-9$ & $6.8900 \mathrm{e}-10$ & $2.5397 \mathrm{e}-10$ & $6.6731 \mathrm{e}-10$ \\
\hline Contact wire2 & $3.2711 \mathrm{e}-9$ & $6.8900 \mathrm{e}-10$ & $6.9946 \mathrm{e}-9$ & $2.0980 \mathrm{e}-9$ & $2.2949 \mathrm{e}-9$ \\
\hline Feeder 2 & $7.1693 \mathrm{e}-10$ & $2.5397 e-10$ & $2.0980 \mathrm{e}-9$ & $6.0704 \mathrm{e}-9$ & $6.4184 \mathrm{e}-10$ \\
\hline Rail & $2.3967 e-9$ & $6.6731 \mathrm{e}-10$ & $2.2949 \mathrm{e}-9$ & $6.4184 \mathrm{e}-10$ & $1.0920 \mathrm{e}-7$ \\
\hline
\end{tabular}

The traction substation is placed to one side,the train is at $10 \mathrm{~km}$, we could get voltage waveform of the $10 \mathrm{~km}$ location as shown in Figure 5:
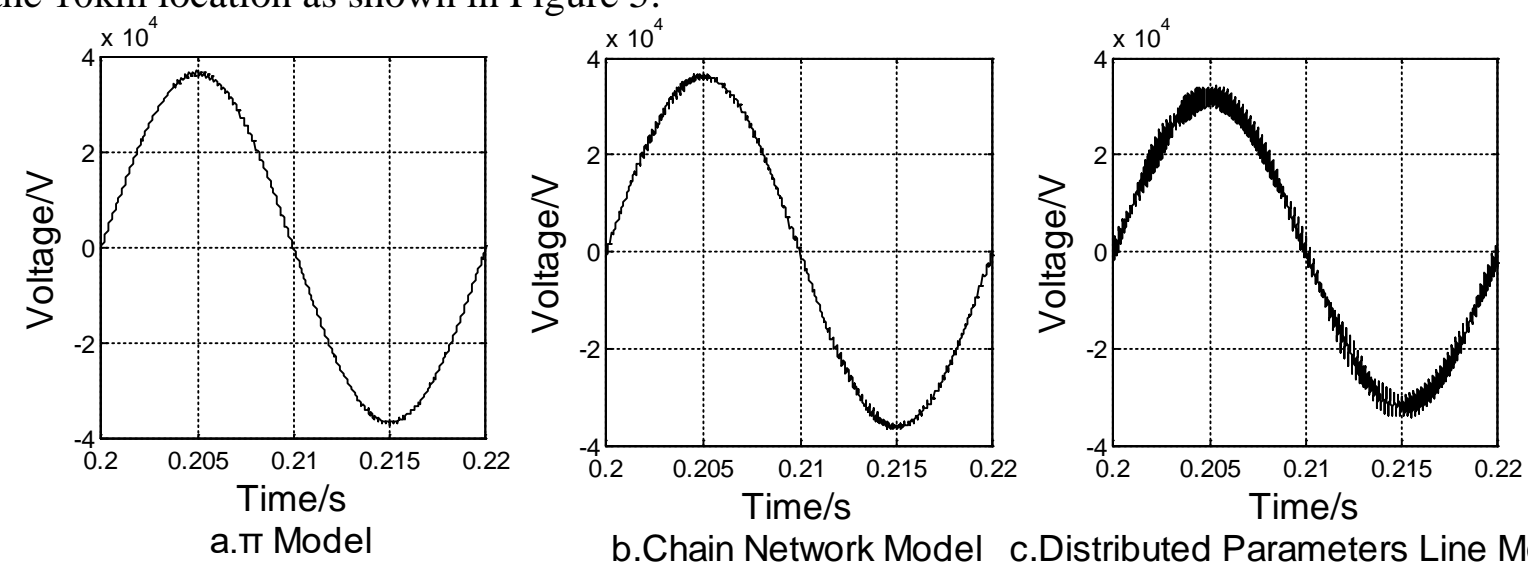

b.Chain Network Model c.Distributed Parameters Line Model

Fig.5. Voltage Comparison of Different Modeling Methods

What is shown to us is that adopting three different ways of modeling has little effect on analysis 
of the voltage amplitude of the fundamental, which is belong to the location of the train. At the peak of the voltage, it can be seen from the left to the right of the three images will appear more obvious.So during the high-frequency resonance analysis of the network voltage, using distribution parameter will have one more obvious effect.

In the network resonance analysis, it often need to analyze impedance characteristics of traction network in different position.In the three modeling methods, chain network model can calculate traction network equivalent impedance value of different locations in one model, which is more convenient,the calculation interval is related to the model unit length. Impedance analysis in different frequency of $20 \mathrm{~km}$ model are as follows in Figure 6:

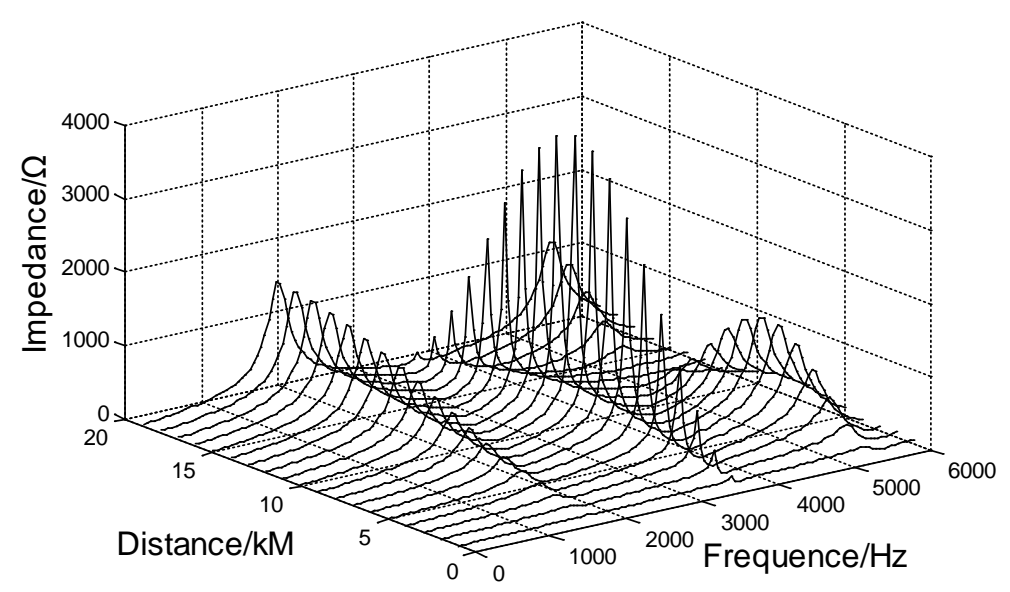

Fig.6. Impedance of 20km Line in Different Position

Though the impedance analysis diagram of the whole network, it is more convenient to see which position is more likely to resonate in which band.

\section{Conclusion}

This paper introduces three modeling methods of traction network in traction power supply system. The network voltage of the train's position is compared with the three simulation models. The results of analysis are as follows:

(1) $\pi$ model circuit is the simplest of the three models,the calculation is small,and the digital space which simulation takes up is small.

(2) The modeling process of multi conductor chain network model is complex, but it can make a fine classification of traction network. This model is often used when it analyses the whole line of traction network voltage and impedance. However, the model takes up a large space in the digital simulation, and the simulation speed is slow.

(3) The distributed parameter model is more prominent in the calculation of the high frequency signal, but the accuracy of the model is limited by the simulation step size. This model can be used in the analysis of the high frequency harmonics which train is located in the specific operation.

\section{References}

[1] Shen, J., Taufig, J.A., Mansell, A.D.: 'Analytical solution to harmonic characteristics of traction PWM converters’, IEE Proc. Electr. Power Appl., 1997, 144, (2), pp. 158-168

[2] Chang, G.W., Lin, H.W., Chen, S.K.: 'Modeling characteristics of harmonic currents generated by high-speed railway traction drive converters’, IEEE Trans. Power Deliv., 2004, 19, (2), pp. 766-773

[3]Hengbin Cui,Wensheng Song,Hui Fang,Xinglai Ge,Xiaoyun Feng.: 'Resonant harmonic 
elimination pulse width modulation-based high-frequency resonance suppression of high-speed railways’, IET Power Electron., 2015, Vol. 8, Iss. 5, pp. 735-742

[4]Yiwang Xiong,Ying Shang,Danhong Tong.: 'Analysis on Harmonic Current of Electrified Railway Traction Network Based on Multi-port Reduced-order Model’, CICED 2012 ,Shanghai, 5-6 Sep. 2012

[5] Liu Xuejun. A Model and its Algorithm of 4-end network Cascaded for the Electrified Railway Traction Network[J]. Journal of the China Railway Society, 1995, 17:32-35

[6] 1. H. Song and H. M.Hwang. Estimation of harmonics on power system on ac electric railway. KIEE Int. Trans. Power Eng., vol. 52B, no. 2, pp.68-79, 2003.

[7] Y. Mochinaga. Higher harmonics resonance on at feeding circuit and countermeasures to suppress it. Trans. Inst. Elect. Eng. Jpn., vol. 114-D, no. 10, 1994. 